\title{
Climate Change Education for Universities: A conceptual framework from an international study
}

\section{Highlights}

- Universities have the potential to play a key role in combating climate change

- It is important to understand the range of implementation strategies chosen globally by Higher Education Institutions to address climate change education

- A conceptual framework for exploring how universities in 45 countries are embedding climate change education into their curricula was developed

- Four approaches are highlighted: Piggybacking, mainstreaming, specialising and connecting (transdisciplinary)

- Practical examples show how climate change education may be implemented across the world.

\begin{abstract}
The role of universities in climate change education (CCE) is of great importance if the scientific, social, environmental and political challenges the world faces are to be met. Future leaders must make decisions from an informed position and the public will need to embed climate change mitigation tools into their work and private life. It is therefore essential to understand the range of CCE strategies being taken globally by Higher Education Institutions (HEIs) and to explore and analyse the ways that HEIs could better address this challenge.
\end{abstract}

Consistent with this research need, this paper offers an analysis of the extent to which HEIs in 45 countries approach CCE and provides a conceptual framework for exploring how HEIs are embedding CCE into their curricula. In addition to the specialist approach (where students choose to study a degree to become experts in climate change adaptation and mitigation tools), the CCE framework developed identifies and highlights three other approaches HEIs can deploy to embed CCE: Piggybacking, mainstreaming and connecting (transdisciplinary). Using data gathered in an explorative international survey involving participants working across academic and senior management, this paper illustrates the different approaches taken and analyses practical examples of current CCE practice from across the world.

Responses from 212 university staff from 45 countries indicated that CCE was highly variable - no clear pattern was identified at the country level, with CCE approaches varying significantly, even within individual HEIs. This plurality highlights the wide range of ideas and examples being shared and used by institutions in very different countries and contexts, and underlines the importance of the independence and autonomy of HEIs so that they can choose the right CCE approaches for them. To highlight the breadth and variety of approaches that were uncovered by our survey, the paper offers a range of examples illustrating how climate change education may be embedded in a higher education context, some of which could be replicated in HEIs across the world. The conceptualisation of CCE 
and the examples given in this paper are valuable for anyone who is thinking about strategies for embedding more climate education in the higher education curriculum.

Keywords: Climate Change Education, Mitigation, Carbon Literacy, HEI, Conceptual Framework

\section{Introduction: The Importance of Climate Change Education}

Climate change and its harmful effects on the planet, people and natural resources is a matter of great concern to both industrialized and developing nations. Global climate change is regarded by $97 \%$ of Climate Change Scientists as a manmade problem and current consensus is that we should aim for a global mean temperature rise of no more than $1.5^{\circ} \mathrm{C}$ from 1990 levels (IPCC, 2018) requiring action on two critical fronts: mitigation and adaptation. The implementation of adaptation and mitigation strategies needs capable policymakers and an informed public. Educated people are more aware of the risks climate change poses and are better equipped to make informed decisions about responses at local, national and international scales. While climate change education is important at all levels, from primary schools to universities (UN CC: Learn 2013), it is the higher education sector that is most in need of developing a systemic approach (Leal Filho, 2010a).

So far, investment in education for climate change has not met the urgent demand, despite the recognition it has received at the international policy level: Article 12 of the Paris Agreement encourages nations to "enhance climate change education, training, public awareness, public participation and public access to information" (UNFCCC, 2015). The Paris Agreement also calls for the creation of new academic programmes across a diverse range of disciplines, to ensure our future professionals have a better understanding of both the challenges posed by climate change and of the tools to be used for mitigation and adaptation (UNESCO 2017). Universities need to encourage both students and staff to engage with the challenges we are facing - to promote research, to develop solutions for climate change mitigation and adaptation and to take a leading role in the public discourse that is necessary. Significant first steps have been taken at many universities (see box 1 and Leal Filho, 2017), but many challenges remain. The scale of change required at universities and beyond is unprecedented and best illustrated through the 'action gap' in figure 1 (Bushell et al 2016). It shows the 'action gap' on climate change between the globally accepted targets for limiting global mean temperature to $1.5^{\circ} \mathrm{C}$ above 1990 levels and current policy and national pledges that will not reach the required reductions. HEIs could be one of the key actors in closing this gap.

Figure 1: Insert figure 1 here (provided separately) here and add reprinted with permission of the Grantham Institute - Climate Change and the Environment

Based on the current state of affairs and need for a better understanding of climate change education, this paper offers a new analytical framework to explore how universities are embedding CCE into their curricula. A common and well-known approach has been to offer specialised programmes and elective modules to students who choose them. However, some might argue that every student need to know about climate change mitigation tools whether this would be in law, business, chemistry or any other discipline. Universities could therefore 
decide to 'mainstream' CCE so that every student addresses the topic in their core curriculum. The research questions in this paper are therefore: what are the different implementation strategies of HEIs to CCE? Is there a preference for one approach? How do these implementation strategies manifest themselves in concrete examples? Finally, do certain countries prefer one approach?

\section{Box 1- Fostering Climate Change at Universities: the International Climate Change Information and Research Programme (ICCIRP)}

Created in 2008 by the Hamburg University of Applied Sciences, the International Climate Change Information and Research Programme (ICCIRP) https://www.hawhamburg.de/en/ftz-nk/programmes/iccirp/ is a leading programme which focuses on education, communication and information on climate change. For many years now, ICCIRP has been supporting the discussion on matters related to climate change at universities. In particular, a conference held every two years under the title "Universities and Climate Change", congregates experts and practitioners interested in approaches, methods and tools to promote teaching and research on climate change. Some of the recent publications include:

- Universities and Climate Change- Introducing Climate Change to University Programmes (Leal Filho, 2010)

- Climate Change Research at Universities -Addressing the Mitigation and Adaptation Challenges (Leal Filho, 2017)

- University Initiatives in Climate Change Mitigation and Adaptation (Leal Filho, LealArcas, 2019)

The publications have focused on the role of higher education institutions in addressing climate change mitigation and adaptation challenges, contributing to the development of this fast-growing field. Further, they include the results of empirical research and offer ideas regarding on-going and future research initiatives.

The CCE framework presented here was developed by adapting Rusinko's (2010) and Godemann et al.'s (2011) Sustainability Education Matrices to CCE and was informed by the responses obtained from a global questionnaire survey undertaken for this paper. It therefore provides an insight into present practice in a wide range of universities and develops an analytical framework that will enable anyone interested in embedding CCE in their institution to critically reflect and systematize their own approach. The developed CCE framework is used here to explore and understand how a diverse range of universities from 45 countries are attempting (or not) to meet the challenge of educating their students in climate change mitigation and adaptation tools, no matter what their chosen programme of study. The framework specifically recognises four different approaches adopted by universities in undertaking CCE: Piggybacking, Mainstreaming, Specialising and Connecting. The 
approaches can be used concurrently through a complimentary methodology. The study recommends the development of curricula that add the relevant climate change adaptation and mitigation tools to each discipline through an incremental approach while taking into consideration staff time and resources costs. Beginning from less resource intensive decisions may well be the overriding strategic way forward. Further studies of a quantitative nature are suggested in order to confirm and elaborate on the importance of contextualisation of the specific approaches.

\section{Conceptualising Climate Change Education}

CCE has been an under-researched topic. There have been only a few attempts to conceptualise CCE and define the associated skills, knowledge and competencies (Mochizuki and Bryan, 2015). Approaches to embed CCE are limited, fragmented and often focused on one discipline (Hindley and Wall, 2017). Even within a specific discipline there is limited research on how CCE could be embedded: Hindley and Wall (2017: p 213) systematically searched the business and management literature and found only five articles out of 1446 on the subject of climate change included the terms 'climate literacy', 'climate change literacy', 'climate change education' or 'curriculum' and 'climate change'. A broader review of the research about CCE strategies by Monroe et al. (2017) resulted in 49 papers, of which only 11 were related to HEIs. These 11 were then split across a variety of different topics such as how to engage and empower learners in climate change mitigation and adaptation tools.

CCE belongs within the field of Education for Sustainable Development (ESD) and several articles have explored this nested relationship. For example, Mochizuki and Bryan (2015: p 9) argue for Climate Change (CC) to be taught within ESD:

"CC has far reaching repercussions for where people can settle, grow food, maintain built infrastructure and rely on functioning ecosystems. It therefore touches upon multiple aspects of sustainable development, ranging from human displacement to food security, economic growth and biodiversity loss. Given that CC encompasses environmental, political, social and economic factors, the holistic framework of ESD is an optimal framework to advance CCE."

Mochizuki and Bryan (2015) therefore suggest that CCE could be taught applying one of the well-known framework of ESD - the four pillars of education as conceptualised in the so called 'Delors Report' to UNESCO in 1996 of the International Commission on Education for the Twenty-First Century (Delors 1996), with a special focus on two of the pillars:

1.Learning to know: Students need to understand the causes and consequences of CC as well as CC mitigation and adaptation tools

2. Learning to do: Students need to develop cross-cutting skills such as coping with one's emotion such as fear, being able to adapt fast to different situations and learning contexts, understanding systems and envisioning different solutions and future scenarios.

However, it needs to be noted that teaching CCE within the context of ESD bears the risk that institutions and academics prefer to focus on less complex topics within the ESD framework than the "super wicked problem" of CC, which according to Bushell et al $(2017$, p.40) has the following key challenges: 
1. CC needs action now but the consequences cannot be seen easily nor understood and measured.

2. Climate is a public good and affects every person in the world, but the vested selfinterests of certain actors hinder the debate.

3. Action (Decarbonisation) needs to happen on an unprecedented timescale.

4. Cognitive dissonance is common with individual believing that climate mitigation needs to happen e.g. reducing flights but not taking personal action to do so.

5. In line with cognitive dissonance many individuals feel that they do not need to act but someone else.

6. Integrating CC mitigation is not seen as the social norm.

Given this background it is understandable that CCE has not been integrated into every curricula of every course in every university, despite the fact that the urgent transformation required on an unprecedented timescale does need exactly the full integration of CCE into the different curricula. As Bushell et al (2017: p.47) point out:

"If a critical mass of the general public started owning the problem, it would become a social norm, thereby promoting further action. Furthermore, creating a strategic narrative through continuous strategic dialogue with relevant audiences could help develop a relevant, flexible and adaptive strategy through a dynamic and iterative process."

$\mathrm{CCE}$ in this context could be one of the means in which to provide the strategic narrative and to make climate change mitigation tools and behaviour the social norm. But are universities embedding CCE on a big scale? Recent research indicates that if at all, CCE is addressed within ESD (Brunstein and King, 2018; Crookes et al, 2018; Leal Filho et al 2016). But there has been no research on implementation strategies specifically for CCE. In this paper we focus in on this question: How do universities embed CCE? Do they mainly offer the opportunity that students can choose a degree in any discipline that focuses on climate change adaptation and/or mitigation tools for example in Geography? Alternatively, do they embed CCE in every course they offer?

These questions are related to the present study in three main ways: firstly, they provide a framework against which questions related to universities' involvement on climate change can be discussed. Secondly, examples given by the different universities can be slotted into the different approaches. Finally, it helps to identify how climate change could be embedded into courses.

To construct a framework that would capture the different possibilities on how universities can embed CCE into their curricula, matrices by Rusinko (2010) and Godemann et al. (2011) of integrating sustainability within management and business education were adapted. Both suggested that new offerings with regards to sustainability can be distinguished on two dimensions: Whether they are incorporated into the existing structure or whether a new structure is established? Moreover, secondly, whether they are integrated into the narrow or the broad curriculum? A combination of these dimensions offers four different quadrants as shown in Figure 2. In this new - adapted - matrix, two quadrants have been retained: Piggybacking and Mainstreaming. Two new quadrants have been developed (and renamed) 
as they better capture the approaches taken in Climate Change Education: Specialising and Connecting.

\begin{tabular}{|c|c|c|}
\hline & Existing Structures & New Structures \\
\hline Narrow curricular & $\begin{array}{l}\text { Quadrant } 1 \\
\text { Piggybacking } \\
\text { Integration of climate change } \\
\text { education (CCE) within existing } \\
\text { structures by adding CCE to } \\
\text { individual sessions of courses or } \\
\text { modules }\end{array}$ & $\begin{array}{l}\text { Quadrant II } \\
\text { Specialising } \\
\text { Creation of specific climate change } \\
\text { modules, courses or degrees such as } \\
\text { a MSc in Climate Change }\end{array}$ \\
\hline Broad curricular & $\begin{array}{l}\text { Quadrant III } \\
\text { Mainstreaming } \\
\text { Integration of climate change } \\
\text { education within existing structures } \\
\text { but with the emphasis on a broader } \\
\text { cross-curricular perspective (entire } \\
\text { curriculum) }\end{array}$ & $\begin{array}{l}\text { Quadrant IV } \\
\text { Connecting (Transdisciplinary) } \\
\text { Integration of climate change } \\
\text { education through new cross- } \\
\text { disciplinary offerings such as a } \\
\text { course on climate change offered to } \\
\text { all student within a university or } \\
\text { faculty integrating teaching content } \\
\text { from different disciplines. }\end{array}$ \\
\hline
\end{tabular}

Figure 2. Matrix to illustrate the integration of climate change education (adapted and modified 'Integration of Sustainability Matrix' Godemann et al., 2011 and Rusinko, 2010).

The four different approaches will be now explained, and some examples are given on how they have been integrated into the curricula of HEIs.

\subsection{Piggybacking}

For many universities (and lecturers) this is the most accessible approach: The existing structure is not changed, climate change education (CCE) is integrated into the existing modules and courses: This might include a case study integrated into a module on food production or some additional books on the reading lists for a law degree. It might mean using a dataset showing the impact climate change has on weather patterns in a quantitative module. Erlandsson et al. (2017) describe how this has been done at Nottingham Trent University in the UK, such as designing a card game to be used in the faculty of education or 
a role-play about the climate change negotiation at the $21^{\text {st }}$ Conference of Parties of the United Nations Framework Convention on Climate Change in Paris in 2015.

\subsection{Mainstreaming}

This approach is also characterised by utilizing existing structures; however, in this case, the university/faculty embeds CCE into a broader curriculum. For example, every discipline in a business degree could address CCE, so a module on accounting could include carbon accounting, a module on human resource management could include carbon literacy, and an operation module might include reduced energy costs and associated carbon reduction. Alternatively, the university has decided that all its graduates should get a basic understanding of climate change mitigation and adaptation.

An excellent example of how to implement climate change topics in teaching and learning practices comes from the University of Dar es Salaam in Tanzania. Their curriculum aims to allow every university student to obtain at least a basic understanding of climate change studies and sustainable development. As a result of this work, the University of Dar es Salaam has become a reference centre for climate change studies (UDCM 2017).

\subsection{Specialising}

This approach utilises new structures to address a rather narrow curriculum. An example could be a new BSc in Environmental Science or a new MSc degree in Climate Change. This approach could add a new structure at a smaller unit such as offering a Minor in Greenhouse Gas Management or a new optional module on Sustainable Development. The MSc in Global Change of the Facultad Politécnica (Universidad Nacional de Asunción), Paraguay, for example, aims to build capacity to conduct practice-oriented research on climate change and variability science and management. Curricula seek to develop common scientific language and basic knowledge across disciplines to face the challenge of interdisciplinarity, and between the academia and society. The ultimate goal of the MScCG programme is to become an agent for sustainability and climate change teaching and research (Nagy et al., 2017).

These specific Masters are often associated with the expectation employers have of future employees to fulfil specialist tasks related to climate change management. We carried out a search on the demand of University graduates and available consultant jobs, focusing on the UN sustainable development goals-SDGs (UN, 2015), environmental sciences, engineering, and management at Climate Change Jobs (March 2018) of the International Institute for Sustainable Development (IISD) (https://community.iisd.org/jobs/). Our search showed that Graduates in interdisciplinary environmental sciences and sustainable development are increasingly in demand, as are environmental engineers and Graduates from a business or economics degree with climate change, sustainability and carbon market as part of their curriculum.

\subsection{Connecting}

This approach could be considered as the most innovative one; here the aim is to cover a broad curriculum with a newly designed offer. This can take very different forms. It could be a SPOC (Small Private Online Course, a version of a MOOC - Massive Open Online Course- 
but only accessible for on-campus students) with a focus on energy or climate change (Dharmasasmita et al., 2016). Alternatively, it could be a module that all Undergraduates have to take in their first year of study such as the module "Science Bears Responsibility" in the Leuphana's Bachelor's Programme (Michelsen 2013). The new module or course might offer to students from different disciplines general information on climate change science for example, which the students will then later adapt to their discipline. Alternatively, students learn in a module or course to reflect on a challenge through the lenses of different disciplines for example a MOOC on food and climate change might look at the problem from the perspectives of agriculture, law, food production, nutrition and so on encouraging students to appreciate and apply transdisciplinary approaches in analysing and solving challenges.

The Carbon Literacy Project in Manchester, UK (Carbon Literacy Certificate, 2017) is an excellent example of this approach. This is a wider project run by Community Interest Company Cooler Projects on behalf of the Carbon Literacy Trust, which includes different sectors -for example, they initiated a successful Carbon Literacy training scheme within the television and film sector to achieve the accreditation as 'sustainable production' (Albert, 2017). Manchester Metropolitan University is one of the participants in the broader Manchester project offering Carbon Literacy training to all its students through the Carbon Literacy for Students (CL4Ss) programme (Dunk et al., 2017). As the Carbon Literacy Project has as one of its principles peer-to-peer teaching (The Carbon Literacy Project, 2017), students are trained to deliver the training to their peers in a cascade-training model. The aims of the CL4Ss training is that each student knows the basic principles of climate change science, understands how it impacts their lives, including their disciplinary area and future job sector, makes an active commitment to reduce their carbon footprint (both now and in future employment), and develops skill in communication to encourage others to do likewise. The university funds this work using its unique Environmental Education Fund, which is an internal mechanism to compensate for the climate costs of student air travel (Dunk et al., 2017). Such a training scheme could be easily copied and embedded in other universities in the world.

\section{Methodology}

This section explains the research approach, data collection and data analysis to evaluate climate change education at universities.

\subsection{Research Approach}

The study followed a mixed approach targeted on experts ( university staff and teaching members) aimed at capturing knowledge rooted on climate change matters (expert sampling) (Sounders et al., 2012) based on an online questionnaire, a quantitative data analysis performed on the data obtained from the questionnaire, and inductive reasoning.

\subsection{Data Collection}

The project team surveyed members of the international higher education community, employed at universities, using the online questionnaire software Survey Monkey. The survey (see Appendix 1), which was anonymised, was performed in the autumn of 2017, during which time a variety of individuals and networks was approached with a request for participation. The request for experts participation was sent via e-mail to university staff and teaching members selected around the world based on the Web of Science (e.g. at least four articles on the studied topic). 
We also contacted people in our professional networks, who worked in higher education and asked them to distribute it widely. Thus, this is a convenience expert-based sample rather than a random sample. The validity of the followed approach is related to its exploratory purpose intended to assist with concept development. Therefore, there is no claim of the reliability of the survey at all universities systematically to gather data for hypothesis testing, but of capturing useful knowledge about trends.

\subsection{Data Analysis}

A total of 237 responses were collected from 45 countries. Of these, 25 were rejected because the respondent either indicated that they did not work at a university $(n=4)$ or because they did not specify their role within the institution, as requested $(n=2)$, or because they were not experts $(n=16)$, leaving a total workable return of 212 responses from 45 countries (Figure 3). The sample collected does not systematically record all nations and various regional populations, and the results are therefore not generalizable to the worldwide academic population. However, through inductive reasoning, some interesting trends within the sample have been identified. Most respondents came from the United Kingdom (22\%), the United States (14\%), Brazil (10\%), Portugal (5\%) and Australia (4\%) (Figure 3). The distribution by regions was as follows: Europe (42\%), South America (21\%), North America (16\%), Africa $(10 \%)$, Asia (5\%) and Oceania (5\%). The first list of items was reviewed by the authors to minimise redundancies and similar items and to ensure that all relevant questions were considered. The questionnaire survey was pre-tested by a panel of academics within sustainability areas at the authors' own universities.

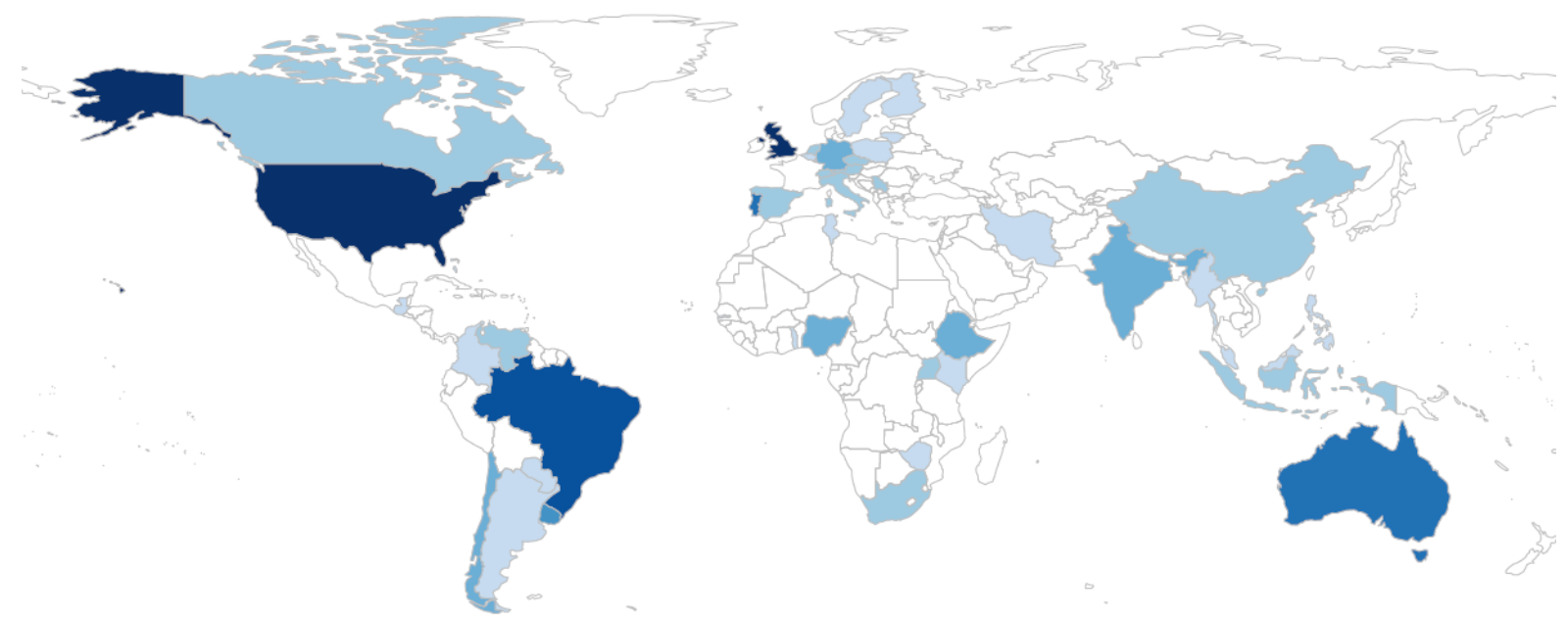

Figure 3. Countries where respondent were working at the time of the survey. Darker colour represents more responses.

When asked to indicate their "Professional role at university", most respondents were employed as academics (e.g. professor, associate professor), researchers (postdoc, research fellow), professional services staff (e.g. sustainability manager) and senior managers (e.g. Dean, Director), though it was often difficult to precisely distinguish between these categories based upon job description alone (we did not ask respondents to classify their role). A total of 44 respondents had a job description that suggested environmental sustainability, energy or climate change was an essential part of their role, excluding academics who work more broadly in these areas (e.g. lecturer in Environmental Sciences). 
The questionnaire asked 23 questions, ranging from opinions about whether anthropogenic climate change is happening to the actions being taken on climate change in respondents' host institutions. Six questions were open-ended and gave rich data. Overall, the vast majority of respondents $(n=205)$ personally believe that "climate change is happening now, caused mainly by human activities".

Overall, the survey questionnaire produced data which covers various topics (Appendix 1) which due to pagination constraints are not all analysed here; further papers are planned to make use of the rich data gathered. The focus in this paper is on how universities have embedded CCE into their curricula. We have therefore chosen to analyse the following openended question for this paper:

1.Please list any planning tools/approaches used by your university to support the implementation of the climate change policy or planning framework.

2.Please list any major current work your university is doing with regard to climate change;

3. Are you collaborating on a project with other institutions/entities vis a vis climate change? If in the affirmative, can you outline the project(s);

4.Please list any major future work your university will be doing with regard to climate change.

We also wanted to understand whether the approaches taken are related to how much importance the university places on matters related to climate change, for example, whether a mainstreaming approach is associated with climate change being of high importance to a university. Therefore we included the following question: 'Your university attaches a lot of importance to matters related to climate change.' This question could be answered on a fivepoint Likert-type scale, from 'strongly disagree' to 'strongly agree' with the option to choose 'do not know'.

The verification and validation of findings were made through a team-expert assessment of the content of the responses, based on a ratio of respondents to question of 10, and getting the feedback from some research participants.

\section{Results and Discussion}

When asked whether "your university attaches a lot of importance to matters related to climate change", approximately twice as many respondents (127) agreed or strongly agreed than disagreed or strongly disagreed (59) with 24 reporting that they don't know and two not answering (Figure 3). It is unclear if those who do not know have stated so out of scepticism or due to lack of information. Patterns of geographical differences were visible. All Venezuelans (3/3), more than half of respondents from Brazil (12/23) and one-third of those from Portugal (4/12) do not feel their university attaches a lot of importance to climate change. In contrast, this figure was only slightly more than one in ten (10/85) for those from the United Kingdom (6/52) and the United States (4/33). This finding could be related to the influence of the media, being consistent with what O'Neil and Boykoff (2010) identified, showing a difference across groups of people and countries.

How respondents reported that their institution implements any policies or plans for climate change fell into several broad categories (Figure 3). These included academic research, public dissemination, technical plans to monitor and reduce carbon emissions or other forms of 
waste, implementing plans through changes to the curriculum and changing governance structures to integrate climate change as an issue into the core business and strategy of the university. Such an approach may include external benchmarking, but only four respondents explicitly mentioned this approach (Figure 4). The different approaches were not limited to particular geographical regions or countries, though implementations via governance approaches were more common in European, American and Australian universities (47 out of $55)$.

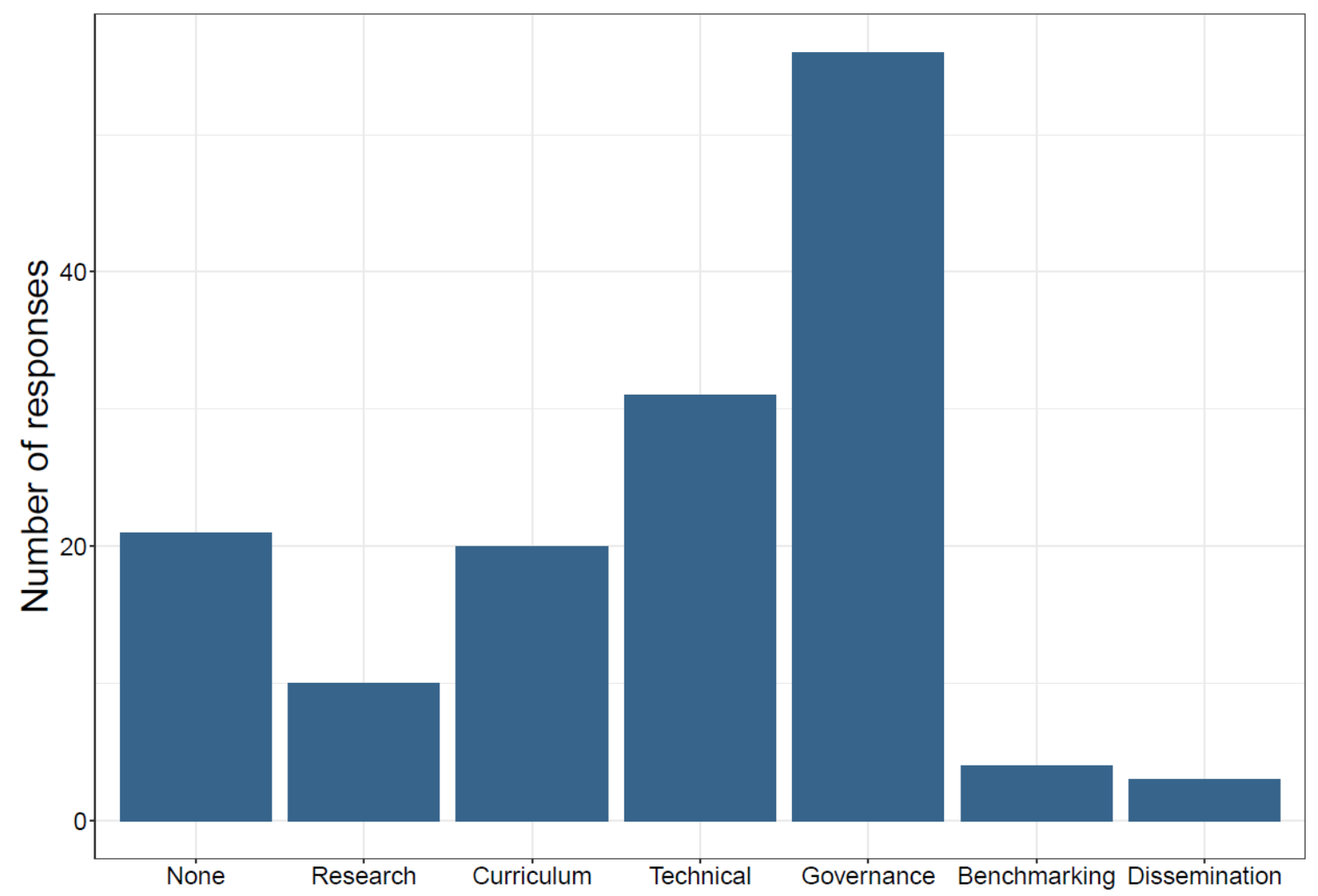

Figure 4. Mechanisms through which respondents reported their university has sought to implement action on climate change

It is apparent that some respondents mentioned more than one implementation mechanism being pursued at their institution. Such a finding has also been identified in previous works e.g. Stoll-Kleemann et al (2001), who worked with different stakeholders. A similar variety of views has also been identified by previous works involving diverse groups (Lorenzoni and Pidgeon 2006).

The 'Technical' responses provided include actions such as monitoring energy usage and waste production, as well as actively seeking to reduce these through practical programmes different light bulbs, more recycling bins. 'Governance' responses include university-wide policies, the establishment of climate change teams and integrating climate (or sustainability more broadly) into centralised planning and corporate strategy. In this context 'curriculum' was only mentioned by 20 respondents; however the survey also included four questions where respondents could choose freely whether they would outline current or future work undertaken with regards to climate change education, climate change research or climate 
change adaptation and mitigation within operations. Here we received hundreds of responses referring to education or/and graduate students research. These are outlined in the next subsection.

\subsection{Analysis of Open-Ended Responses for Questions 1 to 4: Climate Change Education Matrix Patterns}

In this section the Open-Ended Responses for questions 1 to 4 (corresponding to Q 20-23 of the questionnaire in Appendix 1) are analysed aimed at looking for (i) patterns of responses for education (including graduate students research) activities represented as groups of similar responses, for which selected quotations are shown, and (ii) how they relate to the newly conceptualised CCE matrix.

The selected quotations answering Q 1-4 were chosen to represent well the distribution of respondents (from 14 countries). The most common responses for each question were grouped into two groups as follows: [Negative responses], [Education and graduate students research].

Question 1 (Q-1) Please list any planning tools/approaches used by your university to support the implementation of the climate change policy or planning framework.

A high number of responses $(n=172)$ were received, 19 percent of which were negative. Education initiatives were cited by many respondents worldwide but particularly in Europe and North America, and in a less degree in Africa and Latin America. The most common responses can be grouped as follows:

- [Negative responses]: "My University does not have any planning tools/approaches to support the implementation of the climate change policy or planning framework", (Professor, Brazil).

- [Education and graduate students research]: "University-wide Sustainability Plan and Sustainability Charter covering all aspects of teaching, research and operations (Professor, Australia).

Question 2 (Q-2): Please list any major current work your university is doing with regard to climate change.

A high number of responses $(n=181)$ were received for this question, 13 percent of which were negative. Education initiatives were cited by many respondents worldwide but particularly in Europe and North America, and to a lesser degree in Africa and Latin America. The most common responses can be grouped as follows:

1. [Negative responses]: "No major work that I am aware of at this moment. The topic is discussed but not as a primary strategy or goal" (Professor, China); "Work is done by individuals, but not as a university policy" (Former Full Professor, Venezuela).

2. [Education and graduate students research]: "Hosting of the Greater Masaka Regional Centre for Education for Sustainable Development emphasizing community based approaches to climate change" (Senior Lecturer, Uganda); "Hosting a Centre on climate 
change and education, strengthen enrolment in environmental-related courses" (Instructor, University of The Gambia); "Climate change related research projects" (Professors from Bangladesh, Germany and Portugal).

Question 3 (Q-3): Are you collaborating on a project with other institutions/entities vis a vis climate change? If in the affirmative, can you outline the project(s).

A high number of responses $(n=167)$ were received, 27 percent of which were negative. The most common responses can be grouped as follows:

1. [Negative responses]: "No but I know that a large number of Doctoral Thesis assessing both the causes and the mid/long-term consequences of climate change in coastal areas are now being carried out at my University" (Researcher, Spain).

2. [Education and graduate students research]: "Our programme is developed with University of Oxford, Massachusetts Institute of Technology, and Cardiff University "(Associate Professor, South Africa).

Question 4 (Q-4): Please list any major future work your university will be doing with regard to climate change.

The number of responses $(\mathrm{N}=140)$ received was a few less than for the previous ones, 22 percent of which were negative. The most common responses can be grouped as follows:

1. [Negative responses]: "Nothing that I am aware of" (Postdoctoral Researcher, Lithuania); "I don't know, but I wish I did!" (Assistant Professor, USA).

2. [Education and research]: "Developing PhD curriculum in Climate change and conducting high-level research and Climate Change mainstreaming”! (Head of University Department, Ethiopia); "I think my university will enhance the Network for Sustainable Development (RUS) initiative promoted by the University of Milan-Bicocca and adheres to the International Sustainable Campus Network (ISCN) to achieve common sustainability objectives in the management and delivery of university services, also in order to integrate sustainability into research and teaching” (Assistant Professor, Italy).

Many responses for Q1-4 discussed above (Q 20-23 of the questionnaire) show a mix of climate change, energy, sustainability and environmental sciences issues, and many do not specify if they focus on the $\mathrm{CC}$ science or the management (i.e. adaptation or mitigation). This is due to the brevity of responses. Future research would be useful to focus in on this question.

In the following we will first analyse the main responses given concerning climate change education, we will then examine the more 'messier' picture of the various responses often given including examples from the operation, teaching, and research sometimes all in one sentence. We will also discuss whether the respondents gave preference to any of these approaches.

\subsection{Climate Change Education}

\subsubsection{Piggybacking}


For many universities (and lecturers) this is the easiest approach, as the existing educational structures are not changed; instead climate change education (CCE) is integrated into existing modules and courses. Respondents in our survey referred to this approach when they said for example 'There are only isolated contributions from Programs and teachers' (Production Engineering Doctor, Brazil), or 'encouraging some students to conduct research on the topic' (Head of English Department, Tunisia). Some also highlighted that the integration of CCE is not done consistently: 'Two courses are occasionally offered. Work done linked to President's Climate Commitment' (Professor, USA). Piggybacking is also characterised by a very narrow curricular integration, for examples when some respondents answered something along the lines of the following quote, it could be argued that this is still a narrow curricular approach: 'Developed the programme Bachelor of Environmental Design as a prerequisite for Architecture and Landscape Architecture' (Senior Lecturer, Uganda). However, this quote might already indicate a broader curricular approach for the discipline, in this case, architecture and therefore leading over to Mainstreaming. Overall, not many respondents cited examples of piggybacking. One might wonder why the respondents did not give more 'piggypacking' examples. It might be that CCE appears to be so complex that it does not lend itself to piggybacking, or could simply reflect the fact that respondents were not asked specifically to give examples on how CCE is happening at their university so omitted this information. Future research could explore this further.

\subsubsection{Mainstreaming}

HEIs following this approach might integrate CCEs into their teaching policies and strategies and encourage all course leaders to integrate $\mathrm{CCE}$ into their teaching whatever the discipline. In our survey we had a few examples where this approach was taken as illustrated in the two following quotes:

"Part of Climate Change Education Strategy is that climate change education will be made available, accessible and relevant for all undergraduates, whatever their chosen subject, so that the success and hallmark of being a Winchester graduate will include an appreciation of three key issues: the effect on social justice, the ubiquitous impact and, above all, the urgency of the challenges presented by climate change." (Professor, UK)

"Mainstreaming climate change teaching and research into existing environmental and energy courses as well as collaborating with other institutions both within and outside Nigeria on climate change and sustainable development." (Professor, Nigeria)

Some of the 'mainstreaming' activities interacted with other sustainability themes such as the circular economy and using the university campus as a 'living lab'. For example, one respondent reported that their UK-based university has situated its climate change-focused teaching and learning within a wider goal to be carbon neutral by 2040, suggesting a deeply embedded strategy at the institutional level. Therefore, this institution might be on the right pathway to begin 'connecting' activities in the future. Another example of 'mainstreaming' was exemplified by the creation of an Education for Sustainable Development program at a university in Indonesia. Many respondents from other Anglo-American universities also reported some mainstreaming approach in CCE.

\subsubsection{Specialising}


This approach utilises new structures to address a narrow curriculum. One respondent reported a high proportion of students taking a specialist class "About half of all students take a class on the environment and climate change" (Professor, USA). One university in our sample seems to have taken this approach across all levels: "BSc, MSc and PhD courses in Environmental Engineering (started 1977!)”. One respondent linked this approach to policy, strategy and research development: "1. Design and approval of an environment and sustainable development policy, including a derived strategic plan with definite time terms. 2 . The openness to new related careers and research entities in related areas such as an Energy Resources Institute and a Sustainable Development Institute. 3. The approval of PhD and MSc Degrees. 4. The installation of external cooperation research projects on Energy and Climate Change thanks to European Union support and other national and international cooperation agencies." (Director, Guatemala). However, this approach also lends itself to the development of a new structure which does not need to be connected to anything else the university has done before "proposing a major in sustainability studies" (Program Director, US). It is likely that specialising approaches are more accessible to implement in Higher Education systems that enable students to take minor subjects or elective modules or classes, with some systems making specialising difficult, but more work is needed to be able to uncover the explanatory power of different country's Higher Education systems.

Several responses in our survey could be classified as 'specialising, e.g. the creation of specific CCE for both undergraduate and graduate levels $(n=4)$, and a few others offering Climate Change and Sustainability $(n=3)$. It is likely that the brief and focused responses given in the questionnaire could have underestimated this approach. However, specialisingtype approaches are reported as a common practice for several countries in South America (Nagy et al., 2017), and it could be the same in other regions.

\subsubsection{Connecting}

This approach could be considered as the most innovative one; here the aim is to cover a broad curriculum with a newly designed offer, such as an online course or a module that all undergraduates have to take in their first year of study (Michelsen 2013). In our questionnaire we had some examples that such an approach was taken: "Dedicated MOOC in sustainability science" (Research Fellow, Italy) or "Structuring of education network for sustainability, transversal to all undergraduate courses" (Professor, Brazil). Some respondents had plans for the future as outlined in the following quote: "A few academics have tabled an interdisciplinary MSc in Climate Change and Sustainable Development with one of our vicechancellors - we are waiting for feedback." (Associate Professor, South Africa).

An example of deep cross-curricular 'connecting' activity was reported at a Brazilian university: "Structuring of education network for sustainability, transversal to all undergraduate courses" (Professor, Brazil). Some respondents were aware that the activities at their institution fell short of mainstreaming and connecting, such as one reporting that their activities were "department specific-not integrated interdisciplinary yet" (Associate Professor, South Africa).

Finally, some respondents $(n=4)$ discussed elements of piggybacking, specialising and mainstreaming alongside one another, highlighting that in some institutions, several 
approaches may be taking place concurrently - e.g. "To educate the students through some talks and workshops that extend to the surrounding communities. There have also been some general courses on climate change. Some subjects include climate change issues" (Assistant Professor, Venezuela).

\section{Conclusions}

The study undertaken aimed to foster a better understanding of the full range of approaches taken by universities on how to embed CCE. It achieved this by developing a framework for systematising approaches to CCE and then identified the extent to which these approaches were being implemented in a non-random but extensive sample of universities from 45 countries. Its originality lies in the fact that this new framework explores how CCE could be integrated into a university. In addition to the specialisation approach, where universities simply design new educational content for those students who choose them, three further approaches were identified: Piggybacking, Mainstreaming, and Connecting.

The study was explorative and qualitative in nature; therefore the suggested framework would now benefit from a wide quantitative research to confirm some of our first insights that specific approaches are country specific. For example, most respondents from universities in an Anglo-American context (75/85) claimed that their universities attach a lot of importance to climate change and reported a mainstreaming approach in CCE. However, no countryspecific preference for any of the approaches was found and some universities had adopted more than one approach, indicating that CCE is often ad hoc. Understanding the generality of these initial findings will be an important future endeavour.

The levels of responses provided by different groups (e.g. lecturers/professors, administrative staff and decision-makers) refer to the diversity of experiences, and these are useful in offering a wider view of how climate change education is viewed and perceived by the sampled universities. Further studies are therefore needed that zoom in on each of the core activities undertaken by universities such as operations, education and research, and examine how they integrate climate change mitigation and adaptation into these core activities. Indicative questions include: (a) are most universities worldwide already piggybacking? (b) how many universities are mainstreaming CCE into their core curriculum or are aiming to do so, (c) is specialising most often at module or programme level? (d) how many universities are connecting different disciplines by creating new offerings that combine the wisdom and tools of different disciplines together?

Despite its limitations, this paper has offered some plausible examples of how universities utilize the different approaches, some of which could perhaps be adapted in other countries in the world. Universities might use the CCE matrix created for this paper to analyse their offering on CCE and identify their future direction. Each approach has its strengths and weaknesses. Societies need the expertise of specialists who have undertaken particular academic programmes to devise specific policies and practices. Additionally, every graduate needs to have a basic understanding of climate change science and policy (especially of mitigation and adaptation strategies and tools) so that work practices are challenged across all sectors, whether by specialists or non-specialists, and citizens can make informed decisions about the environmental impact of their lifestyles and consumer choices. 
To this end, curricula need to be developed that add the relevant climate change adaptation and mitigation tools to each discipline. This can start on a smaller level, e.g. in a module through piggybacking, or the whole university might revise its curriculum mainstreaming climate change education into all programmes, courses and modules. Alternatively, a university could offer newly designed carbon literacy training to all its students, hence connecting all disciplines. The implications of each approach, especially in respect of the staff time and resources needed to implement them are admittedly comprehensive. However, this paper has highlighted some universities which are among the first movers in this regard. It has also outlined some approaches that are less cost and resource intensive than others, such as making the strategic decision to encourage each academic to include one climate change mitigation tool in the teaching of their discipline. As far as the paper's implications are concerned, it is seen that universities need to more seriously engage and design innovative curricular and extra-curricular approaches on how to integrate climate change education and make them accessible within the HEI sector. The changes at university and faculty level such as integrating climate change education into its learning and teaching strategies need to be further underpinned by the right textbooks and book chapters helping academics to incorporate climate change education into their respective disciplines (Dharmasasmita et al. 2017; Leal Filho, 2017, Molthan-Hill et al. 2017; Nagy et al., 2017 and Leal Filho, 2010).

In conclusion, the current and future level of international attention paid to climate change means that its relevance is likely to increase in the coming years. It is therefore crucial that higher education institutions, especially the ones so far limited to Piggybacking, move forward in the hierarchy, towards Mainstreaming, Specialising and Connecting to handle a problem which is global in nature, but whose impacts are especially felt at the local and regional level.

\section{References}

Albert 2017. Sustainable Film \& TV production training - 'Albert' via BAFTA http://wearealbert.org/help/get-trained (Accessed 05 January 2018)

Brunstein, J., King, J., 2018. Organizing reflection to address collective dilemmas: Engaging students and professors with sustainable development in higher education. Journal of Cleaner Production 203, 153-163.

Bushell, S., Buisson, G.S., Workmann, M., Colley, T., 2017, Strategic narratives in climate change: Towards a unifying narrative to address the action gap on climate change, Energy Research \& Social Science 28, pp 39-49

Bushell, S., Workmann, M., Colley, T. (2016) Towards a unifying narrative for climate change - Grantham Briefing Paper 18 URL: https://www.imperial.ac.uk/grantham/publications/towards-a-unifying-narrative-for-climatechange---grantham-briefing-paper-18.php (Accessed 01 April 2019)

Carbon Literacy Certificate, 2017. http://www.carbonliteracy.com/individual/ (Accessed 05 January 2018) Please contact info@ carbonliteracy.com for more information 
Crookes, P.A., Outram, S., Else, F.C., 2018. Developing a collaborative pilot programme to promote innovation in higher education focusing on the reward and recognition of teaching. J. Furth. High. Educ. 42, 1156-1166

Delors, J., 1996, Learning: The treasure within. Report to UNESCO of the International Commission on Education for the Twenty-first century. Paris: UNESCO

Dharmasasmita, A., Kennedy, E., Puntha, H., Holmes, R., 2017. Climate change and greenhouse gas management, in: Molthan-Hill, P. (Ed), The business student's guide to sustainable management: principles and practice. Principles for responsible management education. PRME book series. Routledge, Abingdon, pp. 410-459

Dharmasasmita, A., Puntha, H, Molthan-Hill, P., 2016. 'Practical Challenges and Digital Learning: Getting the Balance Right for Future-Thinking', On the Horizon: 'Learning for sustainability in the digital world: assessing the opportunities and challenges in higher, adult and vocational education'

Dunk, R., Mörk, J., Davies, J., Davidson, J., Paling, C., Hindley, J., Leigh, S., Tinker, H., 2017. Taking Responsibility for carbon emissions - the evolution of a Carbon Literacy Living Lab. Environmental Scientist. Volume 26 No. 4. pp 88-95.

Erlandsson, L., Molthan-Hill, P., Smith, A., Arntsen, A., 2017. Combating Global Warming Through the Estate and Curriculum - A Whole-Institution Commitment at Nottingham Trent University, in: Azeiteiro, UM et al. (Eds) Higher Education Institutions in a Global Warming World - The transition of Higher Education Institutions to a Low Carbon Economy, River Publishers, Aalborg, Denmark, (in press)

Global Education Monitoring Report UNESCO, 2011. Climate change: Education has a key role. URL: https://gemreportunesco.wordpress.com/2011/12/07/climate-change-educationhas-a-key-role/ (Accessed 05 January 2018)

Godemann, J., Herzig, C., Moon, J. (2011). Approaches to changing the curriculum. Presentation given on the ISIBS Workshop - Session II, University of Nottingham 20/21.10.2011

Hess, D, J, Collins, B, M, 2018. Climate change and higher education: Assessing factors that affect curriculum requirements. Journal of Cleaner Production, 170, pp. 1451-1458. https://www.sciencedirect.com/science/article/pii/S0959652617322187 (Accessed 05 January 2018)

Hindley, A., Wall, T. (2017). A unifying, boundary crossing approach to developing climate literacy. In W. Leal Filho (Ed.), Implementing sustainability in the curriculum of universities: teaching approaches, methods, examples and case studies (pp. 263-278). London, United Kingdom: Springer

IPCC, 2018, Global Warming of $1.5^{\circ} \mathrm{C}$, an IPCC Special Report on the Impacts of Global Warming of $1.5^{\circ} \mathrm{C}$ above Pre-industrial Levels and Related Global Greenhouse Gas Emission 
Pathways, in the Context of Strengthening the Global Response to the Threat of Climate Change, Sustainable Development, and Efforts to Eradicate Poverty. Available at; http://www.ipcc.ch/report/sr15/

Leal Filho, W. (2010a) Climate Change at Universities. Results of a World Survey, in: Leal Filho, W, (ed.) Universities and Climate Change: Introducing Climate Change to University. pp. 1-19, http://www.springer.com/de/book/9783642107504 (Accessed 05 January 2018)

Leal Filho, W. (Ed) (2010b) Universities and Climate Change: Introducing Climate Change to University Programmes. Springer, Berlin.

Leal Filho, W., Shiel, C., Paço, A., 2016. Implementing and operationalising integrative approaches to sustainability in higher education: the role of project-oriented learning. J. Clean. Prod. 133, 126-135.

Leal Filho, W. (Ed) (2017) Climate Change Research at Universities Addressing the Mitigation and Adaptation Challenges. Springer, Berlin.

Leal Filho, W., Morgan, E. A., Godoy, E., Azeiteiro, U. M., Bacelar-Nicolau, P., Veiga Ávila, L., Mac-Lean, C., Hugé, J. (2018) Implementing climate change research at universities: Barriers, potential and actions. Journal of Cleaner Production, Volume 170, pp. 269-277. https://www.sciencedirect.com/science/article/pii/S0959652617320954 (Accessed 05 January 2018)

Lorenzoni, I, Pidgeon, N. (2006) Public views on climate change: European and USA perspective. Climatic Change 17, pp. 445-459.

Michelsen, G. 2013. Sustainable Development as a Challenge for Undergraduate Students: The Module "Science Bears Responsibility" in the Leuphana Bachelor's Programme. Sci Eng Ethics 19: 1505. https://doi.org/10.1007/s11948-013-9489-5 (Accessed 05 January 2018)

Mochizuki, Y., Bryan, A. 2015. Climate Change Education in the context of education for sustainable development: Rationale and principles. Journal of Education for Sustainable Development 9: 4-26

Molthan-Hill, P., Winfield, F., Baddley, J., Hill, S. 2017. Work based learning: Students solving sustainability challenges through strategic business partnerships, in: Flynn, P, Gudić, M., Tan, T. Redefining Success: Integrating the UN Global Compact into Management Education, PRME book series, Greenleaf, Sheffield, pp.

Monroe, M., Plate, R. R., Oxarart, A, Bowers, A., Chaves, W.A. 2017. Identifying effective climate change education strategies: A systematic review of the research. Environmental Education Research. Advance online publication.

Nagy, G.J.,Cabrera, C.,Coronel, G, Aparicio-Effen, M., Arana, I, Lairet, R., Villamizar, A. 2017. 'Addressing climate adaptation in education, research and practice: the CLiVIAnetwork", Int. J. Clim. Change Strateg. Manage., 9:4:469-487, https://doi.org/10.1108/IJCCSM-04-2016-0056_(Accessed 05 January 2018) 
O`Neil , S., Boykoff, M. T. (2010) The role of new media in engaging the public with climate change. In, Whitmarsch, L., O`Neil, S. and Lorenzoni, I. (eds) Engaging the Public with Climate Change. Earhscan, London.

Rusinko, C.A. 2010. Integrating sustainability in management and business education. The Academy of Management Learning and Education 9(3), 507-519

Second Nature, Education for Sustainable Education, Clean Air-Cool Planet, 2011. Higher Education's Role in Adapting to a Changing Climate. http://secondnature.org/publications/higher-educations-role-in-adapting-to-a-changingclimate/ (Accessed 05 January 2018)

Stanford University (2017), School of Earth, Energy \& Environmental sciences, Climate Change Education Project. https://pangea.stanford.edu/programs/outreach/climatechange/ (Accessed 05 January 2018)

Stoll-Kleemann, S. O’Riordan, T., Jaeger, C. 2001. The psychology of denial concerning climate change mitigation measures: evidences from Swiss focus groups. Global Environmental Change, 11. pp. 107-118.

The Carbon Literacy Project 2017. Carbon Literacy Course Kit. http://www.carbonliteracy.com/wp-content/uploads/2017/11/Carbon-Literacy-CourseKit_v1.7.pdf (Accessed 05 January 2018)

University of Dar es Salaam (UDSM) 2017. Centre for Climate Change Studies. UDSM, Dar es Salaam.

UN CC: Learn 2013 The One UN Climate Change Learning Partnership. Integrating Climate Change in Education at Primary and Secondary Level. Geneva.

https://www.uncclearn.org/learning-resources/integrating-climate-change-education-primaryand-secondary-level-interactive (Accessed 05 January 2018)

UNESCO, 2017. UNESCO at COP23. Climate Change Education. Available at: http://unesdoc.unesco.org/images/0026/002600/260083e.pdf

UNFCC (United Nations Framework Convention on Climate Change) 2015. Paris Agreement, http://unfccc.int/paris_agreement/items/9485.php_(Accessed 05 January 2018)

United Nations. 2015. Transforming our world: The 2030 Agenda for Sustainable Development A/RES/70/1. 41pp

United Nations Sustainable Development Knowledge Platform, 2015. Transforming our world: the 2030 Agenda for Sustainable Development https://sustainabledevelopment.un.org/post2015/transformingourworld (Accessed 05 January 2018)

University of Copenhagen, 2017. Master of Science (MSc) in Climate Change. Copenhagen, Denmark. http://studies.ku.dk/masters/climate-change/ (Accessed 05 January 2018) 
CCCS 2017: University of Dar es Salaam, Centre for Climate Change Studies (CCCS), Climate Change and Sustainable Development, Dar es Salaam, Tanzania. http://www.cccs.udsm.ac.tz/masters-program/_(Accessed 05 January 2018)

University of East Anglia, 2017. MSc Climate Change Postgraduate Study. Norfolk, UK, https://www2.uea.ac.uk/study/postgraduate/taught-degree/detail/msc-climate-change (Accessed 05 January 2018) 